\title{
La fiscalidad de los territorios de Ceuta y Melilla
}

José Muñoz Domínguez

\section{Introduccion}

La Univesidad Nacional de Educación a Distancia, Centro Asociado de Melilla, en su número nueve, ha publicado la tesis que bajo el título de La Fiscalidad de los Territorios de Ceuta y Melilla, presenté al Instituto de Estudios de Administración Local en enero de 1984, siendo defendida y aprobada el 13 de diciembre de ese mismo año ante el tribunal constituido al efecto.

Pero desde la terminación de la tesis hasta su publicación han ocurrido acontecimientos trascendetales para nuestra nación, como la adhesión a la Comunidad Económica Europea y la consiguiente adaptación legislativa. Así, por Ley 30/1985, de 2 de agosto, se aprueba el Impuesto sobre el Valor Añadido, columna vertebral de nuestra imposición interior y que incide directamente en nuestras relaciones comerciales y fiscales con la Península e Islas Baleares.

Por ello, parece oportuno ahora acometer un trabajo de sintesis, partiendo de la anterior tesis, que resuma y actualice la fiscalidad de estos territorios y que pueda servir de divulgación no sólo a los empresarios y profesionales de la materia sino también y en general a los residentes de Ceuta y Melilla y a aquellas personas que pretendan relacionarse comercial o turísticamente con nosotros.

\section{Antecedentes históricos}

Desde que las ciudades de Ceuta y Melilla pasaran a la Corona de Castilla gozaron de exención de toda clase de pechos y subsidios. En Melilla, la casa de Medina Sidonia hacía frente a los gastos hasta que en 1556 la Corona hace frente a los mismos. Según el Cronista Oficial de la ciudad de Melilla D. Francisco Mir Berlanga, consta que en 1561, en tiempos del Alcalde Benegas, se percibian unos "derechos de puertas e hierros", precedente al más remoto del actual arbitrio por entrada de mercancías. Posteriormente se estableció una renta "fija y permanente sobre las mercancías que traian los moros, consistente en ocho maravedís sobre cada ferral y cuatro reales de plata por cada quintal de cera". 
Una Real Cédula de 1668 confirma estos privilegios y se mantienen posteriormente por las Reales Cédulas de Carlos II y Felipe V y por las Reales Ordenes de Fernando VII y de Isabel II.

Las ciudades de Ceuta y Melilla, cuando los gastos fueron aumentando, necesitaron obtener sus propios ingresos, cobrando ciertos derechos a la entrada de algunos productos procedentes de Berbería.

La reforma tributaria de Fernández Villaverde hizo que en estas ciudades comenzara a percibirse el Impuesto de Derechos Reales. Posteriormente se exige el Impuesto del Timbre y, en 1926, con Flores de Lemus, la Contribución Industrial, de Comercio y Profesiones. Y así van implantándose los distintos impuestos estatales hasta llegar a la Ley de 30 de diciembre de 1944, antecedente del actual régimen especial de Ceuta y Melilla.

\section{Los territorios francos}

Son puertos francos aquellos que tienen el privilegio de franquicia de derechos de aduana con respecto a ciertos artículos o de forma absoluta. La institución de los puertos francos aparece en nuestra legislación con el Real Decreto de 11 de julio de 1852, que en su artículo primero declara puertos francos en las Islas Canarias los de Santa Cruz de Tenerife, Orotava, Ciudad Real de las Palmas, Santa Cruz de la Palma, Arrecife de Lanzarote, Puerto de Cabras y San Sebastián. Era Ministro de Hacienda Juan Bravo Murillo.

El real Decreto de 13 de enero de 1860 declara al puerto de Ceuta como puerto franco y, posteriormente, los puertos de Ceuta, Melilla y Chafarinas, por Ley de 14 de julio de 1894, eran declarados francos.

Las Ordenanzas de Aduanas aprobadas por Real Decreto de 15 de octubre de 1894, siendo Ministro de Hacienda Amós Salvador, contienen en su apéndice noveno el Reglamento de Puertos Francos.

La Ley de 22 de diciembre de 1955 sobre Régimen económico y financiero de Ceuta y Melilla, reconoce en su preámbulo "la multisecular y gloriosa tradición españolísima de estos territorios". La base primera proclama la nacionalidad espanola de los territorios de Ceuta y Melilla y sus dependencias, de soberanía plena e inalienable.

La base segunda se refiere a "territorios francos" y no a puertos francos. Y así la base tercera declara a los territorios de estas dos ciudades, a sus términos municipales y a sus dependencias de Alhucemas, Vélez de la Gomera y Chafarinas, francos a efectos aduaneros. Por ello será libre la entrada, salida tránsito y transbordo de mercancias, sin exigencias de derechos arancelarios ni gravámenes a la importación o exportación.

La Ley Arancelaria de 1 de mayo de 1960 ratifica el contenido de la de 22 de diciembre de 1955, pues en su artículo segundo al determinar el territorio arancelario, determina que comprende: Los Puertos, Zonas y Depósitos francos que actualmente existen... En dichos territorios serán de aplicación dos regimenes de áreas arancelarias exentas. 
El artículo 241 de la Ley 41/1964, de 11 de junio, de Reforma del sistema Tributario, en su apartado 1, faculta al Gobierno para la aprobación de un texto refundido de los distintos tributos que componen la Renta de Aduanas. En este sentido se había pronunciado la Ley General Tributaria de 28 de diciembre de 1963.

Para dar cumplimiento a lo anterior, se aprueba el Texto Renfundido de los impuestos que integran la Renta de Aduanas, por Decreto de 18 de febrero de 1977. El artículo segundo de este Decreto, al tratar del ámbito de aplicación de los derechos arancelarios de importación, en su número dos, reitera la no aplicación en los territorios de Ceuta y Melilla de este impuesto, salvo en los casos señalados en el artículo tercero, cuya letra c) sujeta la importación de buques extranjeros $o$ de origen extranjero que se abanderen en España, con matriculación en Ceuta y Melilla, excepto los buques pesqueros que tengan menos de doscientas toneladas de registro bruto y seiscientos caballos de vapor y se dediquen preferentemente al abastecimiento de pescado de dichos temitorios.

\section{La imposición estatal en Ceuta y Melilla}

La reforma tributaria de Mon-Santillán, de 23 de mayo de 1845, ha sido hasta fechas recientes la arquitectura de nuestro sistema tributario. Recoge la tributación aragonesa directa y la castellana sobre el consumo. La reforma aumentó los ingresos públicos y el nivel de vida. Adopta el modelo francés.

Tras sucesivas reformas, el cambio más profundo se produce con la Ley de Medidas Urgentes de Reforma Fiscal, de 14 de noviembre de 1977. Esta Ley introduce el Impuesto sobre el Patrimonio de las Personas Físicas, regula el secreto bancario y da una nueva redacción al artículo 319 del Código Penal, regulando el delito fiscal. La etructura de esta reforma es la siguiente:

A) Imposición directa

1. Impuesto sobre la Renta.

1.1. Renta de la Personas Físicas.

1.2. Renta de Sociedades.

2. Impuesto sobre el capital.

2.1 Sobre el Patrimonio.

2.2. Sobre Sucesiones.

B) Imposición indirecta

3. Sobre el Tráfico de las Empresas.

4. Sobre Transmisiones Patrimoniales.

5. Sobre consumos específicos.

5.1. Sobre el Petróleo y derivados.

5.2. Sobre alcoholes, bebidas y tabacos. 


\section{1.- impuesto General sobre la Renta de las Personas Físicas.}

El impuesto recae sobre las rentas obtenidas en España, tanto por residentes como por no residentes. La Ley del Impuesto, de 8 de septiembre de 1978, mantiene la bonificación del 50 por 100 en la parte de la cuota que proporcionalmente corresponda a los ingresos obtenidos en estos territorios, siempre que se justifique que están situados en ellos los inmuebles, explotaciones, actividades o negocios productores de la renta gravada.

\section{2. - Impuesto sobre la Renta de Sociedades}

Se bonificarán en el 50 por 100 las cuotas correspondientes a las entidades que operen en estos territorios. La bonificación quedará limitada únicamente a los beneficios que las entidades justifiquen haber obtenido en estos territorios, siempre que en ellos tengan establecidas fábricas, instalaciones industriales o comerciales que permitan claramente cosiderar a la entidad como operante en los mismos.

El nuevo impuesto sobre Sociedades es creado por la Ley 61/1978, de 27 de diciembre, manteniendo la bonificación del 50 por 100 para los rendimientos e incrementos de patrimonio obtenidos por las entidades que operen efectiva y materialmente en Ceuta y Melilla.

\section{3.- Impuesto extraordinario sobre el Patrimonio}

Se implanta este impuesto en nuestra nación como consecuencia de la Ley 50/1977, de 14 de noviembre, de Medidas Urgentes. Es de carácter transitorio, pues deberá ser sustituido por el Impuesto sobre el Patrimonio Neto.

La Orden del Ministerio de Hacienda de 9 de mayo de 1978 interpreta la disposición final tercera de esta Ley, que sefiala que los impuestos que se crean por la misma se aplicarán en Ceuta y Melilla de acuerdo con lo establecido en la Ley de 22 de diciembre de 1955, en el artículo 229.3 de la Ley de Reforma del Sistema Tributario de 10 de junio de 1964 y en el Decreto 1.891/1964, de 18 de junio.

Ėl Ministerio, con carácter de interpretación auténtica, sienta el criterio de que la referencia de esta disposición final tercera de la Ley 50/1977, a las disposiciones que en la misma se citan como aplicables a Ceuta y Melilla en orden a este impuesto, deberá entenderse en el sentido de que las cuotas de este impuesto de nueva creación se bonificarán en el 50 por 100 cuando los bienes o derechos de contenido económico radiquen o se produzcan, según los casos, en los territorios de Ceuta y Melilla.

\section{4. - Impuesto General sobre Sucesiones}

En la Ley de 6 de abril de 1967 no se contiene norma especifica para los territorios de Ceuta y Melilla. 


\section{5. - Impuesto General sobre el Tráfico de Empresas}

El artículo noveno del Decreto de 18 de junio de 1964 establecía la no aplicación en estos territorios de los apartados a), b), f), g), h), e i) del artículo 186 relativo a este impuesto. Para determinar el lugar de realización de estas operaciones, se estará a lo dispuesto en los artículos 12.2.3 y 13 de la Ley 30/1985, de 2 de agosto, según el Real Decreto-Ley 6/1985, de 18 de diciembre. Por consiguiente no están sujetas al impuesto las siguientes actividades:

- Las operaciones por las que los fabricantes, industriales y comerciantes mayoristas transmitan o entreguen por precio, bienes, mercancias o productos de su fabricación, industria o comercio, cualquiera que sea la forma que adopten. No estarán sujetas, en ningún caso, las operaciones realizadas por los comerciantes minoristas.

- Las entregas de bienes, mercancías o productos que los fabricantes, industriales y comerciantes mayoristas efectúen para destinarlas al comercio en sus establecimientos abiertos al público.

- Las transmisiones o entregas por precio de productos naturales a fabricantes, industriales o comerciantes mayoristas.

- Las importaciones de bienes, mercancías o productos y la posterior transmisión o entrega por precio de dichos bienes, mercancías o productos.

- Las exportaciones de bienes, mercancías o productos de cualquier naturaleza, verificadas por las personas a que se refieren los apartados a) a d) del artículo 186 mencionado, por los agricultores o por quienes se dediquen a esta actividad habitualmente.

- La aplicación que a su producción o comercio al por mayor realicen los industriales, fabricantes o comerciantes mayoristas de los bienes, mercancías o productos que sean objeto de su actividad o comercio.

El artículo 13.3 del Reglamento de 19 de octubre de 1981 mantiene la no sujección al impuesto de las ventas, entregas, transmisiones e importaciones que se realicen en Ceuta y Melilla de bienes, artículos o productos, así como las ventas, entregas y transmisiones desde la Peninsula y Baleares cuando tengan por destino Ceuta y Melilla.

\section{6. - Impuesto General sobre Transmisiones Patrimoniales y Actos Jurídicos Documentados}

Cuando corresponda aplicar los números 6,14 y 15 de la Tarifa, tratándose de Sociedades cuyo único objeto sea realizar negocios en estos territorios y radiquen en ellos sus instalciones, maquinaria, establecimientos e inmuebles, las cuotas correspondientes se reducirán en un 50 por 100 .

Está exenta la constitución y transmisión a título oneroso de concesiones administrativas, cuando se refieran a bienes, obras, servicios o aprovechamientos públicos en Ceuta y Melilla.

El artículo 48 del Texto Refundido de 30 de diciembre de 1980 establece 
que en las ciudades de Ceuta y Melilla se mantedrán las bonificaciones tributarias establecidas en la Ley de 22 de diciembre de 1955.

\section{7.- Los Impuestos Especiales}

Nuestra imposición indirecta ha de configurarse, al igual que en el área comunitaria, sobre dos figuras básicas. El impuesto sobre el Valor Añadido, como impuesto general sobre el consumo de bienes y prestaciones de servicios y los Impuestos Especiales conocidos como "accisas" en la CEE, que agrava el consumo de determinados bienes, superponiéndose al IVA, esto es, no excluyéndolo como ocurre hoy respecto del Impuesto General sobre el Tráfico de las Empresas.

Esta coexistencia se justifica en razón a que el consumo de determinados bienes resulta, en algún sentido, contraproducente para la sociedad por generar unos costes sociales no tenidos en cuenta a la hora de fijar sus precios privados, costes que deben internalizarse mediante la exigencia de un impuesto que, al tiempo de desincentivar tales consumos compense los gastos sociales ocasionados a la comunidad, lo que se logra a través de una imposición especifica que grave selectivamente los consumos no deseados.

Los impuestos especiales se configuran como impuestos indirectos que gravan en fase única la fabricación, la elaboración y, paralelamente, la importación, con repercusión obligatoria del gravamen por parte de fabricantes e importadores.

La Ley de Impuestos Especiales es de 23 de diciembre de 1985 y su Reglamento fue aprobado por Decreto 2.442 de 27 de diciembre del mismo año.

La Ley contempla las siguientes figuras tributarias:

- El Impuesto sobre el Alcohol y Bebidas Derivadas.

- El Impuesto sobre la Cerveza.

- El Impuesto sobre Hidrocarburos.

- El Impuesto sobre las Labores del Tabaco.

El ámbito de aplicación de estos impuestos se circunscribe a la Península e Islas Baleares pero los impuestos sobre el alcohol y sobre la cerveza se extienden a las Islas Canarias. Melilla y Ceuta están, pues, excluidas de la aplicación de estos impuestos, pero al preverse la absorción en el Impuesto sobre las Labores del Tabaco del rendimiento de las rentas de los respectivos monopolios existentes sobre estos productos, también este impuesto se aplica en los territorios de Ceuta y Melilla.

Por consiguiente los Impuestos sobre el Alcohol y Bebidas Derivadas, sobre la Cerveza y sobre Hidrocarburos no se aplican en los territorios de Ceuta y Melilla. El Impuesto sobre las Labores del Tabaco sí es aplicable en estos territorios.

Como el artículo tercero del Reglamento considera exportación la salida de los bienes objeto de cada impuesto de su respectivo ámbito territorial de aplicación y los artículos 42, 72 y 89 declaran exentas estas operaciones, los Alco- 
holes y Bebidas Derivadas, Cervezas e Hidrocarburos procedentes de la Península y Baleares vendrán libres del Impuesto Especial.

\section{8.- El impuesto sobre el Valor Añadido}

La introducción de la tasa sobre el valor añadido ha supuesto en el marco de la Comunidad Económica Europea el paso más importante para la consecución de la armonización fiscal. Esta tasa ha venido a sustituir a la tasa sobre la cifra de negocios, impuesto acumulativo en cascada, que no era considerado neutral. Esta tasa se establece por el Consejo de Europa por la primera directriz de 11 de abril de 1967 y se estructura por la segunda directriz, que es de esa misma fecha. La tercera directriz, de 9 de diciembre de 1969, señala la fecha limite para la implantación, que se fija en 1 de enero de 1972. Pero Italia necesitó ampliación de plazos hasta el 1 de Enero de 1973.

El Consejo de la Comunidad Económica Europea, basándose en el Tratado de Roma y concretamente en sus artículos 99 y 100, a propuesta de la Comisión y visto el parecer de la Asamblea, considerando que el objetivo esencial del Tratado es el establecimiento de un mercado común en el que exista una sana competencia, con características análogas a las de un mercado nacional, considerando que las legislaciones en vigor no respondían a las exigencias de sana competencia y libre circualción de mercancías, acuerda la primera directriz. El interés de este mercado común es el de realizar una armonización de las legislaciones relativas a la tasa sobre la cifra de negocios, que tenga por objeto eliminar, en la medida de lo posible, los factores que puedan falsear las condiciones de concurrencia, permitiendo al propio tiempo conseguir suprimir las imposiciones a la importación y las desgravaciones a la exportación.

El Consejo consideró que el sistema de tasa sobre el valor añadido es de una gran simplicidad, siempre que se perciba de una manera general y que su campo de aplicación y de distribución comprenda todos los estadios, incluyendo las prestaciones de servicios.

$\mathrm{El}$ artículo primero de la primera directriz obliga a los Estados miembros a reemplazar su actual sistema de tasa sobre la cifra de negocios por el sistema común de tasa sobre el valor añadido.

El Impuesto sobre el Valor Añadido se configura en nuestra nación como el tributo básico de la imposición indirecta española. Absorberá la totalidad de los tributos actualmente establecidos sobre la cifra de negocios de las Empresas, determinando la desaparición de los mismos y de los actuales mecanismos de ajustes fiscales en frontera.

Este Impuesto se crea en España por la Ley 30/1985, de 2 de agosto, del Impuesto sobre el Valor Añadido y se reglamenta por Real Decreto $2.028 / 1985$, de 30 de octubre.

Aunque el Impuesto es un tributo de naturaleza indirecta que incide sobre el consumo, se exige fundamentalmente con ocasión de las transacciónes, entregas de bienes y prestaciones de servicios, realizadas en el desarrollo de una 
actividad empresarial o profesional, si bien el mantenimiento de su neutralidad en el comercio internacional hace preciso gravar las importaciones de bienes con independencia de la condición del importador, es decir, tanto si se realizan por empresarios o profesionales como si se efectúan por particulares.

El ámbito especial de aplicación del Impuesto queda limitado al territorio peninsular español e islas Baleares, no extendiéndose a Canarias, a Ceuta ni a Melilla.

La delimitación, a los efectos del IVA, de dos áreas territoriales independientes (el territorio peninsular español y las islas Baleares de una parte y las islas Canarias, Ceuta y Melilla de la otra) hace preciso instrumentar los mismos mecanismos establecidos con terceros países respecto de las relaciones comerciales que se produzcan entre ambas zonas territoriales, al objeto de mantener la neutralidad del Impuesto en los intercambios comerciales. Por ello se define la importación en el territorio peninsular espafiol e islas Baleares como la entrada de bienes en dichos territorios, cualquiera que sea su procedencia, icluso cuando ésta sea de Canarias, Ceuta y Melilla.

Las peculiaridades que encontramos respecto a la aplicación del Impuesto por razón del territorio, son las siguientes:

\subsection{1. - Exenciones relativas a las exportaciones}

Según el artículo 15 del Reglamento están exentas del Impuesto las entregas de bienes enviados con carácter definitivo a Ceuta o Melilla por el transmitente o por un tercero en nombre y por cuenta de éste. La exención está condicionada a la salida efectiva de los bienes del territorio peninsular espanol o islas Baleares.

También quedan exentas estas operaciones cuando son realizadas por el propio adquiriente, cuando no esté establecido en el territorio peninsular español o islas Baleares, o por un tercero en nombre y por cuenta de aquél, cuando se cumplan las siguientes condiciones y requisitos:

1. La expedición tendrá carácter comercial.

2. El adquiriente o tercero deberá entregar al proveedor un acuse de recibo de los bienes en el momento en que sean puestos a su disposición.

3. La salida de los bienes se producirá efectivamente, en el plazo de tres meses siguientes a la puesta a disposición de los mismos.

4. Las declaraciones de envío a Ceuta o Melilla se cumplimentarán por el proveedor y se presentarán a la Aduana por el adquiriente o tercero, remitiendo en el plazo de treinta dias siguientes a la fecha de la salida de los bienes al proveedor el duplicado de las declaraciones con la diligencia de la Aduana que acredite dicha salida.

5. El proveedor deberá conservar a disposición de la administración la documentación correspondiente. 


\subsection{2.- Exportaciones en régimen de viajeros}

Cuando un viajero que resida habitualmente en Ceuta o Melilla a su paso por la Península o islas Baleares realice compras de bienes, estarán exentas del impuesto cuando se cumplan los siguientes requisitos:

a) Que los bienes adquiridos no constituyan una expedición comercial.

Se considerará que no constituyen expedición comercial cuando se hayan adquirido en forma ocasional para destinarlos exclusivamente al uso personal del viajero o de su familia o para regalos a otras personas residentes también fuera del territorio peninsular español o islas Baleares y que, por su naturaleza o cantidad, no pueda presumirse la posibilidad de su utilización en una explotación 0 actividad económica cualquiera.

b) Que el valor unitario de los bienes, incluidos el Impuesto sobre el Valor Añadido e Impuestos Especiales, sea superior a 25.000 pesetas.

c) Que el transmitente expida la correspondiente factura ajustada al modelo publicado en el B.O.E. de 23 de diciembre de 1985.

d) Que los bienes adquiridos salgan efectivamente del territorio de aplicación del Impuesto. Los bienes deberán presentarse en la Aduana de salida en el plazo de los tres meses siguientes a la expedición de la correspondiente factura.

e) Que el viajero adquiriente resida fuera del territorio peninsular español - Islas Baleares, circunstancia que podrá acreditarse mediante el pasaporte, documento nacional de identidad o cualquier otro documento o certificación oficial expedido a estos efectos y cuyos datos deberá hacer constar el transmitente en la factura que expida.

\subsection{3. - Prestaciones de servicios exentas}

Están exentos los trabajos realizados sobre bienes muebles adquiridos en el interior del territorio peninsular español o Islas Baleares y seguidamente enviados con carácter definitivo a Ceuta o Melilla.

Quedan asimismo exentas las prestaciones de servicios, incluidas las de transporte y operaciones accesorias, cuando estén directamente relacionadas con los envíos de bienes a Ceuta o Melilla.

\subsection{4. - Entrega de bienes a Organismos reconocidos}

Quedan exentas estas entregas, cuando el Centro de Gestión y Cooperacion Tributaria haya reconocido oficialmente al Organismo como realizador de actividades humanitarias, caritativas o educativas. Los bienes serán enviados con carácter definitivo a Ceuta o Melilla en el plazo de tres meses siguientes a la fecha de la adquisición.

\subsection{5. - Operaciones asimiladas a las exportaciones}

Están exentos los transportes de viajeros y sus equipajeś por vía marítima 
o aérea que, iniciados en el territorio peninsular español o las Islas Baleares, terminen en Ceuta o Melilla. La exención se extenderá a los transportes de ida y vuelta.

\subsection{6. - Exenciones a la importación de bienes}

\subsubsection{1.- Exenciones por cambio de residencia}

Estarán exentas las importaciones definitivas de los bienes personales usados pertenecientes a personas físicas que trasladen su residencia habitual desde Ceuta o Melilla al territorio peninsular espantol o Islas Baleares, cuando se solicite la exención y se cumplan las reglas que señala el artículo 36 del Reglamento.

Se entenderán por bienes personales los que normalmente puedan considerarse destinados al uso personal o a las necesidades del hogar, comprendiéndose entre ellos el mobiliario, el ajuar doméstico, los vehículos autmóviles de uso privado, los remolques, las motocicletas, las embarcaciones de recreo y los aviones de turismo, así como los instrumentos portátiles de artes mecánicas o liberales necesarios para el ejercicio de la profesión del interesado.

La exención estará condicionada al cumplimiento de los siguientes requisitos:

a) Que los bienes hayan estado en posesión del interesado o sus familiares o se hayan utilizado por un plazo mínimo de seis meses inmediatamente anteriores a la fecha en que se cause baja en la antigua residencia.

b) Que los interesados hayan permanecido efectivamente en su antigua residencia durante un plazo mínimo de treinta meses consecutivos anteriores a la fecha en que se cause baja en la misma.

\subsubsection{2. - Traslado de residencia por matrimonio}

El mobiliario y bienes que integren el ajuar, incluso nuevo, perteneciente a personas que trasladen su residencia habitual desde Ceuta o Melilla al territorio peninsular español o Islas Baleares con ocasión de su matrimonio, quedará exento del impuesto.

La exención comprende también los regalos ofrecidos por quienes tengan su residencia habitual fuera del territorio peninsular español o Islas Baleares, siempre que el valor unitario de cada regalo no exceda de 25.000 pesetas y el total de los importados no sobrepase la cantidad de 125.000 pesetas.

Quedan excluidos de la exención los vehículos con motor mecánico para circular por carretera, remolques, embarcaciones, aeronaves, los productos alcohólicos comprendidos en las partidas 22.03 a 22.09 del Arancel aduanero y el tabaco en rama o manufacturado, sin perjuicio de las cantidades autorizadas con franquicia para el régimen de viajeros. 


\subsubsection{3.- Bienes adquiridos por causa de herencia}

Los bienes personales que hubieran pertenecido a personas con residencia en Ceuta o Melilla, que sean adquiridos por causa de herencia, por personas físicas o entidades sin ánimo de lucro, quedan exentos. En ningún caso la exención alcanzará a los vehículos.

\subsubsection{4.- Efectos personales de estudiantes}

Quedan exentos los efectos personales y objetos de mobiliario usados que pertenezcan a estudiantes que, teniendo su residencia habitual en Ceuta o Melilla, vayan a residir temporalmente al territorio peninsular español o Islas $\mathrm{Ba}$ leares para realizar sus estudios.

Se incluyen en la exención los objetos e instrumentos usados que utilicen en sus estudios, como libros, objetos de escribania y dibujo, calculadoras, máquinas de escribir y bienes análogos.

Se consideran efectos personales y objetos de mobiliario los objetos y ropa destinados al uso personal y los muebles o artículos destinados al amueblamiento o equipamiento normal de una vivienda.

La extensión quedará condicionada al cumplimiento de los siguientes requisitos:

a) Los bienes tendrán que haber estado en posesión del interesado por un plazo mínimo de seis meses inmediatamente anteriores a la fecha de la importación, circunstacia que se acreditará mediante la correspondiente factura de adquisición o, en su defecto, por el estado de los bienes que evidencie su utilización por el indicado plazo.

b) El mobiliario deberá ser el que se destine normalmente al amueblamiento de la vivienda o habitación en que vaya a residir el estudiante.

c) Se concederá una vez por cada año escolar.

\subsubsection{5.- Residencia secundaria}

Quedan exentos los efectos personales y objetos de mobiliario úsados que se importen por residentes en Ceuta o Melilla, cuando se destinen a una residencia secundaria en el territorio peninsular espanol o Islas Baleares.

Los efectos y mobiliario son los indicados en el epigrafe anterior. En cuanto a los requisitos, serán los siguientes:

a) El importador acreditará ser propietario de la vivienda secundiaria o haberla tomado en arriendo por un período mínimo de doce meses.

b) La vivienda secundaria no podrá ser arrendada o subarrendada durante la ausencia del interesado.

Los interesados deberán presentar relación detallada de los bienes. No podrán ser transmitidos, cedidos o arrendados en los doce meses siguientes a su importación, pues en caso contrario quedarán sujetos al pago del Impuesto. 


\subsubsection{6.- Empresas que cesen en su actividad}

También quedan exentos los bienes de inverión pertenecientes a empresas que cesen definitiva y totalmente en su actividad en Ceuta o Melilla y trasladen su sede o creen un establecimiento permanente en el territorio peninsular español o Islas Baleares para iniciar una actividad similar.

Se excluyen de esta exención:

a) los medios de transporte que no sean instrumentos de producción o de servicios.

b) Las provisiones destinadas al consumo humano o a la alimentación de los animales.

c) Los combustibles y las existencias de materias primas, productos semielaborados o terminados.

Habrán de cumplirse los requisitos establecidos en el número 6 del artículo 36 del Reglamento.

\subsubsection{7.- Régimen de viajeros y pequeños envíos}

Gozarán de exención las importaciones realizadas por los viajeros de bienes contenidos en sus equipajes en las condiciones y con los requisitos siguientes:

a) La exención sólo alcanzará a los bienes que no constituyan expedición comercial cuando su valor global no exceda de 25.000 pesetas y si los viajeros fuesen menores de quince anos, hasta un valor global de 8.000 pesetas.

b) Se entiende por equipaje personal el que el viajero conduce normalmente y presenta en la Aduana en el momento de su llegada, así como el que presente posteriormente, si justifica que ha sido registrado como equipaje a la salida de origen mediante el correspondiente documento expedido por la compania que realice el transporte.

c) Estas mercancías no constituirán expedición comercial cuando sean de exclusivo uso personal de los viajeros o de su familia o se destinen normalmente a ser ofrecidas como regalos y, en todo caso, cuando su importación tenga carácter ocasional.

d) También podrán importarse con exención los siguientes bienes, sin que e valor de los mismos deba tenerse en cuenta en la determinación de los límites de valor global de 25.000 y 8.000 pesetas, respectivamente, señalados anteriormente:
a) Tabacos:
Cigarrillos ....................4 400 unidades
Pequeños cigarros de un peso máximo de
3 gramos por unidad ................. 150 unidades
Cigarros ........................ 75 unidades
Tabaco de fumar ..................400 gramos
b) Bebidas alcohólicas, destiladas y espirituosas 
de una graduación superior a

22 por 100 de volumen . ................ 1,5 litros

Bebidas destiladas y espirituosas, aperitivos a base

de vino o de alcohol de una graduación alcohólica

igual o inferior a 22 por 100 de volumen; vinos

espumosos y vinos de licor $\ldots \ldots \ldots \ldots \ldots \ldots \ldots \ldots 4$ litros

Vinos suaves $\ldots \ldots \ldots \ldots \ldots \ldots \ldots \ldots \ldots \ldots \ldots \ldots \ldots$ litros

c) Perfumes $\ldots \ldots \ldots \ldots \ldots \ldots \ldots \ldots \ldots \ldots, 75$ gramos

Aguas de aseo ...................... 3/8 litro

d) Café $\ldots \ldots \ldots \ldots \ldots \ldots \ldots \ldots \ldots \ldots \ldots \ldots \ldots$ gramos

Extractos y esencias de café ............ 300 gramos

Té ........................... 150 gramos

Extractos y esencias de té ...............60 gramos

Los viajeros de menos de diecisiete años no se benefician de fránquicia alguna para las mercancías señaladas en las letras a) y b) anteriores.

Los viajeros de menos de quince años no se benefician de franquicia alguna para las mercancías senaladas en las letras a), b) y d) anteriores.

En cuanto a los pequeños envíos de mercancías reimitidos por un particular residente en Ceuta o Melilla y destinado a otro particular que tenga su residencia habitual en el territorio peninsular español o Islas Baleares, también quedan exentos. Estas mercancías no constituirán expedición comercial cuando sean de exclusivo uso personal o se destinen normalmente a ser ofrecidas como regalos y, en todo caso, cuando su importación tenga carácter ocasional. El valor global no deberá exceder de 10.000 pesetas y deberán entregarse al destinatario sin contraprestación alguna.

\subsubsection{8. - Otros bienes importados}

Asimismo quedarán exentas las condecoraciones otorgadas por las autoridades de Ceuta y Melilla a personas que tengan su residencia habitual en el territorio peninsular español o Islas Baleares.

También las copas, medallas y objetos similares que tengan carácter meramente simbólico y que sean el objeto de un premio a la participación en Ceuta - Melilla, en actividades artísticas, científicas, deportivas, de servicios públicos o determinados acontecimientos relevantes por parte de personas con residencia habitual en el territorio peninsular español o Islas Baleares.

Están exentos los bienes que, en concepto de obsequio y con carácter ocasional se importen por personas que hayan realizado una visita oficial a Ceuta - Melilla y que los hubiesen recibido de las autoridades con ocasión de dicha visita. Igualmente los que se importen por personas que efectúen una visita oficial al territorio peninsular español o Islas Baleares para entregarlos a las autoridades con ocasión de dicha visita. Y, asimismo, los que se envíen a las autoridades o entidades oficiales del territorio peninsular español o Islas $\mathrm{Ba}$ leares por las autoridades o entidades oficiales de Ceuta y Melilla, en prueba de amistad o buenas relaciones. 
Igualmente quedarán exentos los bienes destinados al acondicionamiento o a la alimentación en ruta de animales que, procedentes de Ceuta o Melilla, sean conducidos por el territorio peninsular español o Islas Baleares en cualquier medio de transporte, siempre que se encuentren a bordo de los medios de transporte y se utilicen o distribuyen en el curso de dicho recorrido.

\subsubsection{9.- Publicaciones oficiales, impresos y documentos diversos}

Estarán exentas las importaciones de los documentos y publicaciones siguientes:

a) Las publicaciones oficiales de carácter turístico, como listas y anuarios de hoteles de Ceuta o Melilla o catálogos de horarios relativos a los servicios de transportes prestados desde dichos territorios, cuando se destinen a su distribución gratuita y no se contenga en ellos más de un 25 por 100 de publicidad comercial.

b) Los documentos, como folletos, libros, revistas, guías, anuncios, fotografías, mapas calendarios, etc., para su distribución gratuita con fines de propaganda general sobre viajes a Ceuta o Melilla, o para asistir a manifestaciones de carácter cultural, deportiva, turística, religiosa o profesional, cuando no contengan más de un 25 por 100 de publicidad comercial privada.

Asimismo quedan exentas las importaciones de los siguientes documentos:

a) Los planos, dibujos técnicos, copias, descripciones y demás documentos análogos importados para la obtención o ejecución de pedidos destinados a Ceuta o Melilla, o para participar en concursos organizados en el territorio peninsular español o Islas Baleares.

b) Los documentos destinados a ser utilizados en exámenes organizados en el territorio peninsular español o Islas Baleares por instituciones establecidas en Ceuta y Melilla.

c) Los formularios, etiquetas, títulos de transporte y documentos similares expedidos por empresas de transporte u hoteleras establecidas en Ceuta o Mebilla a sus oficinas de viajes establecidas en el territorio peninsular español o Islas Baleares.

d) Los impresos oficiales editados por organismos oficiales y los impresos conforme a modelos internacionales dirigidos por asociaciones de Ceuta 0 Melilla a las asociaciones correspondientes situadas en el territorio peninsular español o Islas Baleares para su distribución.

\subsubsection{0.- Reimportaciones de bienes}

Están exentas las reimportaciones de bienes exportados temporalmente a Ceuta o Melilla, cuando se cumplan los siguientes requisitos:

a) Que los bienes exportados temporalmente a Ceuta o Melilla no se hayan adquirido al amparo de las exenciones previstas para las exportaciones u ope- 
raciones asimiladas a las exportaciones, contempladas en los artículos 15 y 16 del Reglamento y anteriormente reseñadas.

b) Que los bienes no hayan sido objeto de una entrega desde que tuvo lugar la salida de los mismos del territorio peninsular español o Islas Baleares hasta su posterior entrada en Ceuta o Melilla.

c) Que la reimportación de los bienes se efectúe por la misma persona a quien la Administración autorizó la salida de los mismos.

d) Que los bienes se reimporten en el mismo estado en que salieron, sin haber sufrido otro demérito que el producido por el uso autorizado por la Administración, incluido el supuesto de realización de trabajos lucrativos fuera del territorio peninsular español e Islas Baleares.

\subsection{7. - Devoluciones en la exportación}

El Decreto 1.255/1970, de 16 de abril, estructuraba la desgravación fiscal a la exportación. Era definida como la devolución, mediante un acto administrativo único, por la Hacienda Pública, en favor de los exportadores, de la totalidad o parte de la tribulación indirecta efectivamente soportada durante los procesos de produción, elaboración y comercialización, por las mercancias objeto de exportación definitiva.

La Disposición Final segunda de la Ley del Impuesto sobre el Valor Añadido, Ley 30/1985, de 2 de agosto, deroga, entre otras disposiciones la desgravación fiscal a la exportación, pero crea otro mecanismo que viene a sustituir al régimen anterior.

Y así el artículo 85 del Reglamento trata de las devoluciones en la exportación. Los sujetos pasivos que, durante el año natural inmediato anterior, hubieran realizado exportaciones definitivas o envíos con carácter definitivo a Ceuta o Melilla por importe global supeior a 20.000 .000 de pesetas, tendrán derecho a la devolución del saldo a su favor existente al término de cada periodo de liquidación hasta el limite resultante de aplicar el tipo impositivo general del impuesto, es decir el 12 por 100 , al importe total, en dicho período, de las exportaciones y envíos mencionados.

En cuanto a quienes hubieran realizado operaciones por importe global inferior a la mencionada cifra o igual, irán practicando el régimen de deducciones previsto en el artículo 59 y siguientes y ejercitarán el derecho en las correspondientes declaraciones-liquidaciones de cada período.

Ya vimos anteriormente que las exportaciones están exentas del impuesto y que por consiguiente los bienes enviados a Ceuta y Melilla vienen sin esta carga tributaria, pero además el exportador podrá deducirse periódıcamente los impuestos que haya soportado como consecuencia de la elaboración, comercialización, etc. del producto. Esto permite que los productos enviados a estos territorios puedan hacerlo única y exclusivamente por el valor del producto, sin carga tributaria alguna.

Pero si en el régimen ordinario, debido a la transparencia del sistema, esto 
es posible, resulta sin embargo más difícil en el régimen simplificado.

\section{La imposición local en Ceuta y Melilla}

La estructura de la fiscalidad local, con ligeros retoques, ha continuado siendo la del Estatuto municipal de 8 de marzo de 1924. En su prólogo se decía que la anterior ley, derogada, de 2 de octubre de 1877 , con su criterio centralizador y absorbente, oponía al ciudadano un muro muchas veces infranqueable. Rota la traba, continuaba diciendo, las energías locales, antes cohibidas, podrán ahora desenvolverse ampliamente. Si el cauce viejo era angosto y avaramente medido, ninguno le aventajará al nuevo en holgado y espacioso.

La Ley 48/1966, de 23 de julio, modifica parcialmente el régimen local. Tras numerosas vicisitudes se aprueba un nuevo texto, la Ley $41 / 1975$, de 19 de noviembre, de Bases del Estatuto de Régimen Local, que se articula parcialmente por Decreto 3.250/1976, de 30 de diciembre.

Posteriormente la Ley 44/1978, de 8 de septiembre, reguladora del Impuesto sobre la Renta de las Personas Físicas, transforma en tributos de carácter local a anteriores impuestos estatales, tales como la Contribución Rústica y Urbana, Cuota de Licencia Fiscal del Impuesto sobre Actividades y Beneficios Comerciales e Industriales y Cuota de Licencia Fiscal del Impuesto sobre el Rendimiento del Trabajo Personal.

La ya crónica situación estructuralmente deficitaria de las Corporaciones Locales se pretende paliar abordando algunos problemas urgentes, aún cuando la solución sea transitoria, tal como explica el preámbulo del Real DecretoLey 11/1979, de 20 de julio, sobre medidas urgentes de financiación de las Corporaciones Locales. Es preciso asegurar, se dice, que las Corporaciones democráticamente elegidas estén dotadas con los recursos indispensables para el desempeño de sus funciones.

La fiscalidad local, de régimen común y por tanto aplicable a los territorios de Ceuta y Melilla queda, pues, configurada por los siguientes tributos:

- Tasas.

- Contribuciones especiales.

- Impuestos.

- Recargos sobre impuestos estatales.

\section{1.- Tasas municipales}

Las tasas pueden establecerse por la utilización privativa o por el aprovechamiento especial de bienes o instalaciones de uso público municipal. También pueden establecerse por la prestación de servicios o la realización de actividades de la competencia municipal.

Entre las tasas por utilizaciones privativas o aprovechamientos especiales podemos citar, entre otras, las siguientes: 
- Desaguie de canalones.

- Ocupación del subsuelo de terrenos de uso público.

- Entrada de vehículos a través de las aceras y las reservas para aparcamiento exclusivo, carga o descarga de mercancias.

- Terrazas, miradores, balcones, marquesinas, toldos y otras instalaciones semejantes.

- Postes, cajas, palomillas, de distribución o de registro, aparatos para venta automática y otros análogos.

- Quioscos en la vía pública.

- Puestos, casetas de venta.

- Escaparates y vitrinas.

- Rodaje.

En cuanto a las tasas por prestación de servicios y realización de actividades, el artículo 19 del Decreto 3.250 ya mencionado, contempla, entre otras, las siguientes:

- Por documentos expedidos.

- Licencias urbanísticas.

- Licencias de apertura de establecimientos.

- Prevención y extinción de incendios.

- Inspección sanitaria en general y análisis químicos, bacteriológicos y cualesquiera otros de naturaleza análoga.

- Cementerio.

- Alcantarillado.

- Recogida domiciliaria de basuras.

- Agua potable.

- Matadero y mercados.

- Inspección en materia de abastos.

- Enseñanzas especiales en establecimientos municipales.

- Museos, exposiciones, bibliotecas.

\section{2. - Contribuciones especiales}

El artículo 23 del Real Decreto 3.250/1976 establece la procedencia de la imposición de contribuciones especiales para la ejecución de obras o para el establecimiento, ampliación o mejora de servicios municipales, siempre que a consecuencia de aquéllas o de éstos, además de atender al interés común o general, se beneficie especialmente a personas determinadas, aunque dicho beneficio no pueda fijarse en una cantidad concreta.

El artículo 26 enumera las obras y servicios que dan lugar a la imposición obligatoria de contribuciones especiales, siendo numerosos los supuestos contemplados. Pero los Ayuntamientos de Ceuta y Melilla vienen atendiendo servicios de carácter provincial, dada la peculiaridad de sus territorios y mediante una extensión generosa en la interpretación y dado el carácter potestativo que el artículo 143 del texto que comentamos confiere a la imposición de contribu- 
ciones especiales por las Diputaciones, no vienen aplicando contribuciones por la realización de sus obras o el establecimiento, mejora o ampliación de servicios.

\section{3.- Imposición municipal}

Según el artículo 41 del Real Decreto 3.250 las Corporaciones que no utiliœn todos los tributos autorizados, pueden ver mermadas sus participaciones en los impuestos estatales. Constituyen la imposición local los impuestos siguientes:

- Sobre solares.

- Sobre la radicación.

- Sobre la circulación de vehículos.

- Sobre el incremento del valor de los terrenos.

- Sobre gastos suntuarios.

- Sobre la publicidad.

\subsection{1. - Impuesto sobre solares}

Grava los terrenos que tengan la condición de solares cuando no estén edificados o sólo existan en ellos construcciones insuficientes, provisionales, paralizadas, ruinosas o derruidas.

También grava los terrenos calificados urbanos o urbanizables programados o que vayan adquiriendo esta última condición, siempre que no tengan la condición de solar.

Según el apartado quinto de la Orden de 20 de diciembre de 1978, que aprueba la Ordenanza Fiscal reguladora, disfrutarán de una bonificación permanente del 50 por 100 en la cuota tributaria los terrenos que estén situados en los territorios de Ceuta y Melilla y sus dependencias.

\subsection{2. - Impuesto sobre la radicación}

Constituye el hecho imponible la utilización o disfrute, para fines industriales y comerciales y para el ejercicio de actividades profesionales y comerciales y para el ejercicio de actividades profesionales, de locales de cualquier naturaleza, situados en el término municipal. Pero el artículo 62 del Decreto 3.250 limita la aplicación a las capitales de provincia y municipios que tengan una población de derecho superior a 100.000 habitantes. No obstante, los Ayuntamientos que no reunan estas condiciones podrán solicitar su aplicación al Gobierno.

Por no haber hecho uso de la facultad indicada anteriormente, estos Ayuntamientos no vienen aplicando el impuesto. 


\subsection{3. - Impuesto sobre circulación de vehículos}

El hecho imponible lo constituye la circulación o posibilidad de circular por las vías públicas de los vehículos de tracción mecánica. Es de imposición obligatoria. El número 3 del artículo 82 del Real Decreto 3.250 trata de las bonificaciones en el impuesto, sin que recoja ninguna por razón de territorio.

\subsection{4. - Impuesto sobre el incremento del valor de los terrenos}

El hecho imponible lo constituye el incremento de valor que experimente un terreno durante el periodo impositivo. El impuesto se aplica tanto a terrenos que se transmitan por cualquier título como a terrenos sobre los que se constituya o transmita un derecho real de goce limitativo del dominio o a terrenos que pertenezcan a personas jurídicas.

No se reconoce bonificación alguna por razón de territorio, aplicándose sus disposiciones integramente.

\subsection{5. - Impuesto sobre gastos suntuarios}

Los hechos imponibles son los siguientes:

- El importe de las ganancias obtenidas como consecuencia de apuestas cruzadas en espectáculos públicos.

- Las cuotas de entradas de socios en sociedades o círculos deportivos o de recreo, siempre que las mismas sean superiores a 10.000 pesetas.

- El disfrute de toda clase de viviendas cuyo valor catastral supere los 10.000.000 de pesetas.

- El aprovechamiento de los cotos privados de caza y pesca. tos.

Los Ayuntamientos de Ceuta y Melilla no vienen aplicando estos impues-

\subsection{6.- Impuesto sobre la publicidad}

La imposición sobre la publicidad es regulada ampliamente por el Decreto $3.250 / 1976$, que le dedica los artículos 106 a 117 . El hecho imponible es la exhibición o distribución de rótulos y carteles con finalidad publicitaria. Se consideran fiscalmente rótulos los anuncios, fijos o móviles, litografiados o impresos y los luminosos. No se recogen bonificaciones por razón de territorio.

\section{4.- Tributos locales de carácter real \\ - Contribución territorial urbana.}


Configurada como "tributo local de carácter real" por la Ley $44 / 1978$, de 8 de septiembre, grava la utilización, goce o posesión, en virtud de un derecho real, de los bienes de naturaleza urbana.

Según el artículo 12.2 del Texto Refundido de este impuesto, aprobado por Decreto 1.251/1966, de 12 de mayo, las fincas situadas en estos territorios gozarán de una bonificación permanente del 50 por 100 de las cuotas. Para las nuevas construcciones, según el artículo 12 del Texto Refundido, modificado por Decreto $1.049 / 68$ de 27 de mayo y Decreto-Ley 11/1979, de 29 de julio, durante el tiempo de construcción y cinco años después de la terminación total o parcial, se reduce la base a la que corresponda al suelo de la finca y, en su caso, a la parte terminada.

\subsection{1.- Contribución territorial, Rústica y Pecuaria}

Configurada también como "tributo local de carácter real" por la Ley 44/1978 de 8 de septiembre, grava la propiedad o posesión de bienes y derechos de naturaleza rústica y pecuaria, las actividades agrícolas, forestales, ganaderas o mixtas y la actividad ganadera independiente.

Conforme al artículo 11 del Decreto 2.230/1966, de 23 de julio se desgravarán en el 50 por 100 las cuotas devengadas en estos territorios.

\subsection{2.- Licencia Fiscal de actividades Profesionales y de artistas}

Constituye el hecho imponible el mero ejercicio, de la actividad profesional y de artistas, según el Texto Refundido de 2 de marzo de 1967.

Se desgravarán en el 50 por 100 las cuotas de Licencia de los profesionales que ejerzan en estos territorios.

\subsection{3.- Licencia Fiscal de Actividades Comerciales e Industriales}

Constituye el hecho imponible el mero ejercicio, por cuenta propia o en comisión, de las actividades comerciales e industriales tipificadas en el Texto Refundido de 29 de diciembre de 1966 e Instrucción de 27 de marzo de 1981.

Se bonificarán en el 50 por 100 las actividades que se ejerzan en estos territorios. Los vendedores al por mayor domiciliados y residentes en Ceuta y Melilla podrán exportar al Reino de Marruecos los productos propios de su industria o comercio sin estar obligados a satisfacer cuota de Licencia por estas operaciones (Art. 10 del Texto Refundido modificado por Decreto 1.049 de 27 de mayo de 1968). 
VI Especial consideración al Arbitrio sobre importación de Mercaderías

$\mathrm{El}$ apoyo jurídico de este arbitrio, término que hoy día sustituiríamos por el de impuesto, lo encontramos en la Ley de 30 de diciembre de 1944. Pero sus precedentes son remotos. Como ya se dijo anteriormente desde que las ciudades de Ceuta y Melilla pasaran a la Corona de Castilla gozaron de exención de toda clase de pechos y subsidios. En Melilla, la casa de Medina Sidonia hacía frente a los gastos hasta que en 1556 la Corona hace frente a los mismos. Según el Cronista Oficial de la ciudad de Melilla, D. Francisco Mir Berlanga, consta que en 1561, en tiempos del Alcalde Benegas, se percibian unos "derechos de puertas e hierros", precedente al más remoto del actual arbitrio por entrada de mercancias. Posteriormente se estableció una renta "fija y permanente sobre las mercancias que traian los moros, consistente en ocho maravedis sobre cada ferral y cuatro reales de plata por cada quintal de cera".

El Gobierno General de la Plazas de Soberanía, por Ordenanza del Alto Comisario de 12 de diciembre de 1938, para la reforma administrativa de los Ayuntamientos de Ceuta y Melilla, autoriza la percepción desde uno de enero de mil novecientos treinta y nueve, con destino al presupuesto ordinario, de un recargo de importación marítima o terrestre de mercaderías, que sustituiría al tradicional que se venía percibiendo.

Haciendo uso de esta facultad, el Ayuntamiento de Melilla estableció para el ejercicio de 1939 y sucesivos un impuesto sobre importación de mercaderías, que abarcaría la cuantía del 5 por 100 "ad valorem" y la cuota benéfico-social que la Aduana Marroquí percibía por las importaciones a la Zona del Protectorado.

El más próximo antecedente del sistema actual es la Ley de 30 de diciembre de 1944, que pretende promover en Ceuta y Melilla un desarrollo económico y también social, que no se consiguio. Los Ayuntamientos quedan dotados de recursos excepcionales pero al carecer estos territorios de suficientes bases imponibles los resultados fueron escasos.

Una comisión interministerial es encargada de estudiar esta problemática, enfocándose bajo una nueva perspectiva. Así llegamos a la Ley de 22 de diciembre de 1955 sobre Régimen económico y financiero de Ceuta y Melilla.

El preámbulo reconoce "la multisecular y gloriosa tradición españolísima de estos territorios". Se trata ahora de mirar al futuro no sólo por lo que respecta a los territorios en sí mismos sino también en relación a la evolución de los territorios vecinos y a la proyección de España en el Norte de Africa.

La Disposición Transitoria Tercera de esta ley dispone que se seguiría recaudando el actual arbitrio "ad valorem". Por ello volviendo a la Ley de 30 de diciembre de 1944 observamos que su preámbulo reconoce la especial situación geográfica y su peculiar régimen administrativo, que obliga a ambos Ayuntamientos a atender no sólo obligaciones propiamente municipales sino otras de carácter provincial. 
Pero no solamente la Ley de 1944 reconoce el arbitrio sino también la disposición adicional segunda del Texto Refundido de 24 de junio de 1955 , de Régimen Local, y el apartado segundo de la Base 19 de la Ley 41/1975, de 19 de noviembre, también de Régimen Local.

Como indica el Reglamento de este impuesto, aprobado por el Ayuntamiento de Melilla el 6 de mayo de 1977, se gravan las mercancías que entren en el territorio municipal con un tipo "ad valorem". La locución latina empleada se usa para indicar que una mercancía importada paga un derecho de entrada proporcional a su valor, por lo que su recaudación no sufre las consecuencias de la inflación.

La Renta de este impuesto comprende:

1. Derechos "ad valorem" a la importación.

2. Derechos menores.

2.1. Tránsitos.

2.2. Depósito o almacenaje.

2.3. Multas.

La principal obligación del contribuyente es la de presentar una declaración que detalle el hecho imponible, acompanada de la factura original del proveedor.

Se entiende como base imponible, según el artículo décimo, el valor de la mercancía expresado en pesetas. Clasifica este artículo las mercancías en las siguientes clases:

1. Mercaderías adquiridas en territorio nacional.

2. Mercaderías extranjeras importadas.

3. Mercaderías en régimen de alquiler.

En las mercaderías adquiridas en territorio nacional, el importe queda determinado por el valor "F.O.B.".

En las mercancías extranjeras importadas se determinará el valor por el sistema "C.I.F.".

Según las mercancías, los tipos impositivos oscilan del medio al diez por ciento del valor.

VI La adhesión a la Comunidad Económica Europea

La adhesión comporta para Ceuta y Melilla ciertas adaptaciones y transformaciones tanto en el régimen comercial como en el fiscal. El régimen peculiar aplicable a estos territorios está recogido particularmente en los siguientes documentos o disposiciones:

- Artículos 25, 155, 186 y 187 del Acta de Adhesión.

- Protocolo número 2 sobre Canarias, Ceuta y Melilla.

- Declaraciones comunes sobre el Protocolo número 2. 
- Anexos I y II del Acta.

- Actas de conclusiones de la Conferencia de 15 de marzo, 29 de marzo y 7 de junio de 1985.

El punto de partida en las negociaciones ha sido la aceptación de la legislación comunitaria por España pero introduciendo excepciones en la aplicación a los territorios de Ceuta y Melilla, dadas sus características de situación, extensión geográfica, población, recursos y los regímenes especiales que tienen desde hace años. A estos rasgos diferenciales hemos de añadir la preeminencia del sector servicios en ambas ciudades, sobre todo el comercio de bazar.

Los dos grandes principios aceptados para estos territorios, de importancia capital para su futuro, son los siguientes:

1. La integración en el Territorio Ampliado de la Comunidad.

2. La exclusión del Territorio Aduanero ampliado de la Comunidad.

\section{1. - La integración en el territorio ampliado de la Comunidad}

El artículo 227 del Tratado de Roma, modificado por el artículo 24 del Acta de Adhesión, en su número 1 establece: "El presente Tratado se aplicará al Reino de Bélgica, a la República Federal de Alemania... y al Reino de España".

Por consiguiente los territorios de Ceuta y Melilla, como partes del territorio español, quedan comprendidos en el territorio comunitario. Sin embargo, según el Protocolo número 2, artículo 1, apartado 1, los productos originarios de Ceuta y Melilla o importados en estas ciudades procedentes de terceros paises no serán considerados al exportarse a la Comunidad ampliada como mercancías que reúnan las condiciones de los artículos 9 y 10 del Tratado. Por ello, en estos intercambios se aplicará la legislación relativa a terceros países. Pero los productos originarios de estos territorios, según el Protocolo número 2, articulo 2, podrán entrar en la Península e Islas Baleares libremente, con exención de derechos de aduana, desde el 1 de enero de 1986, pero en el resto del territorio comunitario se aplicarán los derechos de aduana, aún cuando se irá produciendo gradualmente un desarme arancelario al ritmo y en las condiciones que se preveen en los artículos 30, 31 y 32 del Acta de Adhesión, como veremos más adelante.

Los productos pesqueros originarios de Ceuta y Melilla, comprendidos en las partidas que se indican en el artículo 3, del Protocolo número 2, se beneficiarán de la exención de derechos de aduana al ser introducidos en la Península e Islas Baleares pero no tendrán la consideración de productos en libre práctica, tal como se define en el artículo 10 del Tratado, es decir no podrán circular libremente hacia otro estado miembro. Pero se beneficiarán del desarme arancelario al ritmo y en las condiciones previstas en el artículo 173 del Acta de Adhesión cuando se envíen al resto del territorio comunitario.

Los productos originarios del territorio comunitario penetrarán libremente en estos territorios, con exención de derechos de aduana y de exacciones de 
efecto equivalente, según el artículo 3 del Tratado de Roma y el 6 del Protocolo número 2. La supresión de los derechos de aduana se repite en los artículos 9,12 y 13 del Tratado.

\section{2. - La exclusión del Territorio aduanero ampliado de la Comunidad}

Ceuta y Melilla, al estar excluidas del Territorio Aduanero comunitario, no aplicarán la Tarifa Exterior Común (T.E.C.), pudiendo mantener el actual arbitrio por entrada de mercaderías por lo que a terceros paises se refiere. Pero el régimen aplicado a estas mercancías no podrá ser ni menos ni más favorable que el aplicado por la Comunidad a estos terceros paises, respetándose, por consiguiente, los acuerdos preferenciales existentes o que puedan celebrarse.

\section{3.- El desarme arancelario}

El calendario del desarme arancelario es el siguiente:

$\begin{array}{ccc}\text { Años } & \begin{array}{c}\text { Reducción } \\ \%\end{array} & \begin{array}{c}\text { Reducción } \\ \text { acumulada } \%\end{array} \\ 1 \text { de marzo 1986 } & 10,0 & 10,0 \\ 1 \text { de enero 1987 } & 12,5 & 22,5 \\ 1 \text { de enero 1988 } & 15,0 & 37,5 \\ 1 \text { de enero 1989 } & 15,0 & 52,5 \\ 1 \text { de enero 1990 } & 12,5 & 65,0 \\ 1 \text { de enero 1991 } & 12,5 & 77,5 \\ 1 \text { de enero 1992 } & 12,5 & 90,0 \\ 1 \text { de enero 1993 } & 10,0 & 100,0\end{array}$

España ha obtenido siete años para reducir a cero sus aranceles con la Comunidad. Esto quiere decir que a partir del tercer año habrán caído algo más del 50 por 100.

El ritmo indicado anteriormente habrá de ser seguido por los Ayuntamientos de Ceuta y Melilla en su desarme del actual arbitrio por entrada de mercaderias, pero como ya hemos indicado sólo por lo que respecta a los productos comunitarios, que en 1 de enero de 1993 penetrarán libremente. Los productos de terceros países podrán penetrar pagando el correspondiente arbitrio, que será ajustado en caso de existencia de acuerdos preferenciales. Por ello se hace necesario reconvertir el actual arbitrio sobre entrada de mercaderias, buscando una nueva figura impositiva que supla la merma de recursos que estos Ayuntamientos han comenzado ya a experimentar. 